Aim of the study: Expression of oestrogen and progesterone receptors is a very powerful and useful predictor. Because the response rate to hormonal treatment in breast cancer is associated with the presence of oestrogen and progesterone receptors, assess ment of the receptor expression profile allows for prediction of breast cancer response to hormonal treatment. The aim of this study was to assess whether the expression of receptors for oestrogen (ER) and progesterone $(P R)$ in the tumour tissue of patients with invasive breast cancer correlated with tumour histological type, histological grade of malignancy, tumour size, and lymph node status.

Material and methods: Materials consisted of histological preparations derived from patients treated for invasive breast cancer. Evaluations were conducted with histopathological and immunohistochemical methods using suitable antibodies.

Results: Among 231 cases of breast cancer 18 invasive lobular carcinomas (ILC) and 213 invasive ductal carcinomas (IDC) were diagnosed. Taking the histological type of tumour into account, oestrogen receptor-positive reaction was observed in $74.2 \%$ of IDC and $77.8 \%$ of ILC, and the positive response to PR was observed in $67.1 \%$ of IDC and $61.1 \%$ of ILC. Considering the histological grade, ER- in the largest percentage $(72 \%)$ was observed in second-grade (G2) invasive carcinomas. Similarly, PR expression (75\%) was found in the largest percentage in second-grade (G2) carcinomas. Based on our own studies and data from literature, it appears that the ER (+) status is an indicator of good prognosis, because it points to a less aggressive cancer, in which overall survival and disease-free time is longer in comparison with ER (-) tumours.

Conclusions: Determination of ER status may, therefore, have significant clinical value and is widely used in routine pathological diagnostics.

Key words: invasive ductal carcinoma (IDC), invasive lobular carcinoma (ILC), oestrogen receptor (ER), progesterone receptor (PR).

Contemp Oncol (Pozn) 2015; 19 (3): 220-225 DOI: $10.5114 /$ wo.2015.51826

\section{The role of oestrogen and} progesterone receptors in breast cancer - immunohistochemical evaluation of oestrogen and progesterone receptor expression in invasive breast cancer in women

\author{
Anna M. Badowska-Kozakiewicz ${ }^{1}$, Janusz Patera ${ }^{2}$, Maria Sobol $^{1}$, \\ Jacek Przybylski ${ }^{1}$
}

${ }^{1}$ Department of Biophysics and Human Physiology, Medical University of Warsaw, Warsaw, Poland

2Department of Pathomorphology, Military Institute of Health Services, Warsaw, Poland

\section{Introduction}

Expression of oestrogen receptors (ER) and progesterone receptors (PR) is a very powerful and useful predictor. Because the response rate to hormonal treatment in breast cancer is associated with the presence of ER and PR, assessment of receptor expression profile allows clinicians to predict breast cancer response to hormonal treatment [1-3]. The higher the content of ER and PR in breast cancer, the greater the likelihood of response to hormonal therapy $[4,5]$. In patients with advanced breast cancer, in those classified as $\operatorname{ER}(-) / P R(-)$ the response rate to hormonal treatment is $10 \%$, in the group of $E R(-) / P R(+)$ patients it is $32 \%$, in patients with $\operatorname{ER}(+) / P R(-)$ it is $40 \%$, and in patients with $E R(+) / P R(+)$ it is $73 \%$ [1]. The occurrence of ER and $\mathrm{PR}$ expression is associated with histological type of breast cancer. Lobular and tubular cancers are characterised by a high incidence of oestrogen and progesterone receptors. In these types of cancers, receptors are present in a greater percentage of cases than in other carcinomas $[6,7]$. The same dependence has been demonstrated for the progesterone receptor [6]. Many authors agree that the ER expression is in inverse relation to the size of the primary tumour [6, 8].

A similar relationship was described for the progesterone receptor [8, 9], but not all authors confirm this relationship [10]. Expression of oestrogen receptors is also associated with age and menopausal status. Oestrogen receptor is more frequently detected in breast cancers in postmenopausal women than in premenopausal women $[11,12]$ and more frequently in older women than younger ones [13]. Expression of ER and PR is not constant and changes with disease progression [14]. Typically, the number of cells expressing ER and/or PR progressively decreases with disease progression [15]; an example of this is the inverse relationship between expression of ER and the size of the primary tumour. Many authors agree that the prognosis is better in the case of patients whose tumours exhibit ER and/or PR expression than in patients whose cancers do not show such expression [16]. But opinions on the value of oestrogen and progesterone receptors as prognostic factors are divided. In light of the above information, it seemed like an interesting topic.

The aim was to determine whether expression of ER and PR in tumour tissue of patients with invasive breast cancer correlated with tumour histological type, histological grade of malignancy, tumour size, and lymph node status. 


\section{Material and methods}

The materials consisted of histological preparations derived from patients treated for invasive breast cancer. Histological and immunohistochemical studies were performed at the Department of Pathology of the Military Medical Institute in Warsaw. Samples of tumours were fixed in $10 \%$ buffered formalin phosphate. Paraffin blocks were cut into sections with a thickness of $4 \mu \mathrm{m}$. The resulting sections were stained with different methods for diagnostic purposes. Preparations stained with haematoxylin and eosin were used to identify tumour type (WHO classification) and histological grade of malignancy.

Immunohistochemistry was performed using the EnVision TM + complex HRP DakoCytomation (DAKO) (EnVision $^{\text {TM }}$ Dual Link System-HRP, DAB+, Code: K4065). In order to determine the expression of steroid receptors, monoclonal antibodies against receptors for oestrogen (Monoclonal Mouse Anti-Human Oestrogen Receptor alpha, 1 : 50 dilution, Clone: 1D5, Code: IR654, DAKO) and progesterone (Monoclonal Mouse Anti-Human Progesterone Receptor, 1 : 400 dilution, Clone: PgR636, Code: IR068, DAKO) were used. The study was conducted as follows: sections were incubated in an incubator at $60^{\circ} \mathrm{C}$ overnight and then dewaxed. The next step was to reveal the epitope by heating slides in a buffer for 40 minutes. Subsequently, preparations were left at room temperature for 20 minutes. Preparations were rinsed in buffer, and then endogenous peroxidase was blocked in $3 \% \mathrm{H}_{2} \mathrm{O}_{2}$. In the next step, preparations were incubated with an appropriate antibody. After incubation, preparations were rinsed in a buffer for 10 minutes and then incubated with the reagent (Visualization Reagent) for 30 minutes. After incubation with the reagent the preparations were washed in TBS (Tris-Buffered Saline, Code: S1968) pH 7.6 for 10 minutes, and then preparations were incubated with 3,3'-diaminobenzidine (DAB) (Substrate - Chromogen Solution) for 10 minutes to visualise the colour reaction. At the end of the procedure haematoxylin preparations were stained and preparations were sunk in Canadian balm. Subsequently, colour reactions were evaluated according to a scale that takes into account the extent and intensity of staining of nuclei in cancer cells. Nuclear staining in $>10 \%$ of tumour cells was considered positive for ER and PR.

The $\chi^{2}$ test was used to compare ER and PR expressions among different cases. To assess the relationship between steroid receptor expression and tumour histological type, histological grade of malignancy and clinical stage of tumour, the Mentel-Haenszel test (package StatsDirect) was used. Differences were considered statistically significant at $p \leq 0.05$.

\section{Results}

Pathological examinations were performed in $231 \mathrm{pa}-$ tients suffering from invasive breast cancer. The ages of the patients ranged from 34 to 86 years, and the mean age was 52 years. The patients were divided into two age groups: > 50 years and < 50 years. Among 231 cases of breast cancer, 18 invasive lobular carcinomas (ILC) and 213 invasive ductal carcinomas (IDC) were diagnosed. De- pending on the histological grading, the largest group of invasive carcinomas consisted of grade 2 cancers (G2), and the least numerous group were first grade cancers (G1). Among invasive ductal carcinomas (IDC), most diagnosed cancers were second grade (G2) (65\%) (Table 1).

Analysing the pre-operative staging of studied cancers, it was found that the largest group among the IDC tumours were those described as stage T1c (38\%) and $\mathrm{T} 2$ (46\%) (T1c - larger than $1 \mathrm{~cm}$, up to $2 \mathrm{~cm}$ in diameter, T2 - tumour larger than $2 \mathrm{~cm}$ but not exceeding $5 \mathrm{~cm}$ in diameter). Among ILCS, the largest group were stage T2 (38\%) tumours (Table 1). Statistically significant differences were found for cancers in T4 stage ( $p=0.0225)$ (Table 1).

During the study we also assessed the status of the lymph nodes, noting that in all investigated invasive carcinomas (IDC, ILC) women with invasive breast cancer without metastasis to regional lymph nodes (pNo) (59.3\%) constituted the largest group (Table 1).

In immunohistochemical studies, expression of ER was observed in the nuclei of cancer cells. Expression of these receptors was demonstrated in $78 \%$ of patients in the age group younger than 50 years, and in $22 \%$ of patients in this age group there was no expression of ER. In the same age group, in $80 \%$ of patients, expression of PR was found, and $20 \%$ of patients showed no expression of PR. In women over 50 years old (postmenopausal) ER was detected in $73 \%$ of patients, while PR expression was observed in 64\%, but there was no expression of PR in $36 \%$ of cases. Taking into account the histological type of tumour, a positive reaction for oestrogen receptor was observed in $74.2 \%$ of IDC and $77.8 \%$ of ILC, and the positive response to PR was observed in $67.1 \%$ of IDC and $61.1 \%$ of ILC (Table 2, Fig. 1). Considering the histological grading, ER expression in the greatest percentage $(72 \%)$ was observed in invasive second grade (G2) carcinomas. Similarly, PR expression in the largest percentage (75\%) was found in second-grade carcinomas (G2) (Table 3). Statistically significant correla-

Table 1. Clinicopathological characteristics of studied groups

\begin{tabular}{|c|c|c|c|}
\hline & \multicolumn{2}{|c|}{ Type of tumour } & \multirow[t]{2}{*}{$p \leq 0.05$} \\
\hline & IDC (\%) & ILC (\%) & \\
\hline \multicolumn{4}{|c|}{ Tumour grade } \\
\hline G1 & 5 & 0 & 0.7363 \\
\hline G2 & 65 & 89 & 0.1747 \\
\hline G3 & 30 & 11 & 0.1510 \\
\hline \multicolumn{4}{|c|}{ Tumour size } \\
\hline $\mathrm{T} 1$ & 1 & 0 & 0.3619 \\
\hline T1a & 3 & 0 & 0.9481 \\
\hline $\mathrm{T} 1 \mathrm{~b}$ & 8 & 6 & 0.8691 \\
\hline T1c & 38 & 28 & 0.4087 \\
\hline $\mathrm{T} 2$ & 46 & 38 & 0.5349 \\
\hline T3 & 1 & 11 & 0.0611 \\
\hline T4 & 3 & 17 & 0.0225 \\
\hline \multicolumn{4}{|c|}{ Lymph-node } \\
\hline $\mathrm{pNx}$ & 4 & 0 & 0.8685 \\
\hline pNO & 59 & 60 & 0.8711 \\
\hline pN1 & 23 & 17 & 0.7131 \\
\hline pN2 & 8 & 6 & 0.9289 \\
\hline pN3 & 6 & 17 & 0.1848 \\
\hline
\end{tabular}


Table 2. The percentage of tumours exhibiting positive and negative response to oestrogen and progesterone receptors in tumour cells according to histological type of tumour

\begin{tabular}{|c|c|c|c|c|c|c|}
\hline \multirow[t]{3}{*}{ Type of tumour } & \multicolumn{3}{|c|}{ ER (\%) } & \multicolumn{3}{|c|}{ PR (\%) } \\
\hline & \multicolumn{3}{|c|}{ Expression of steroid receptors } & \multicolumn{3}{|c|}{ Expression of steroid receptors } \\
\hline & negative & positive & $p \leq 0.05$ & negative & positive & $p \leq 0.05$ \\
\hline IDC & 55 & 158 & \multirow[t]{2}{*}{0.7367} & 70 & 143 & \multirow[t]{2}{*}{0.6026} \\
\hline ILC & 4 & 14 & & 7 & 11 & \\
\hline
\end{tabular}

Table 3. The percentage of tumours positive or negative for the presence of oestrogen and progesterone receptors depending on the histological grade of tumour malignancy, the tumour size and the status of regional lymph-node involvement

\begin{tabular}{|c|c|c|c|c|c|c|}
\hline & \multicolumn{3}{|c|}{ ER (\%) } & \multicolumn{3}{|c|}{ PR (\%) } \\
\hline & \multicolumn{3}{|c|}{ Expression of steroid receptors } & \multicolumn{3}{|c|}{ Expression of steroid receptors } \\
\hline & negative & positive & $p \leq 0.05$ & negative & positive & $p \leq 0.05$ \\
\hline \multicolumn{7}{|c|}{ Tumour grade } \\
\hline G1 & 3 & 5 & 0.9427 & 4 & 5 & 0.9329 \\
\hline G2 & 53 & 72 & 0.023 & 51 & 75 & $<0.001$ \\
\hline $\mathrm{G} 3$ & 44 & 23 & 0.0027 & 45 & 20 & 0.002 \\
\hline \multicolumn{7}{|c|}{ Tumour size } \\
\hline T1 & 2 & 1 & 0.9748 & 3 & 0 & 0.2156 \\
\hline T1a & 2 & 4 & 0.7806 & 4 & 3 & 0.9119 \\
\hline $\mathrm{T} 1 \mathrm{~b}$ & 3 & 9 & 0.2710 & 3 & 10 & 0.0843 \\
\hline T1c & 37 & 37 & 0.9807 & 30 & 40 & 0.1750 \\
\hline $\mathrm{T} 2$ & 41 & 46 & 0.4457 & 48 & 44 & 0.5376 \\
\hline T3 & 5 & 1 & 0.7072 & 3 & 2 & 0.9460 \\
\hline $\mathrm{T} 4$ & 10 & 2 & 0.0191 & 9 & 1 & 0.01228 \\
\hline \multicolumn{7}{|c|}{ Lymph-node } \\
\hline Nx & 5 & 6 & 0.7291 & 5 & 3 & 0.3231 \\
\hline NO & 49 & 63 & 0.0443 & 52 & 62 & 0.0763 \\
\hline N1 & 22 & 23 & 0.7845 & 20 & 24 & 0.3379 \\
\hline N2 & 12 & 6 & 0.1932 & 12 & 6 & 0.1294 \\
\hline N3 & 12 & 5 & 0.0588 & 11 & 5 & 0.0975 \\
\hline
\end{tabular}

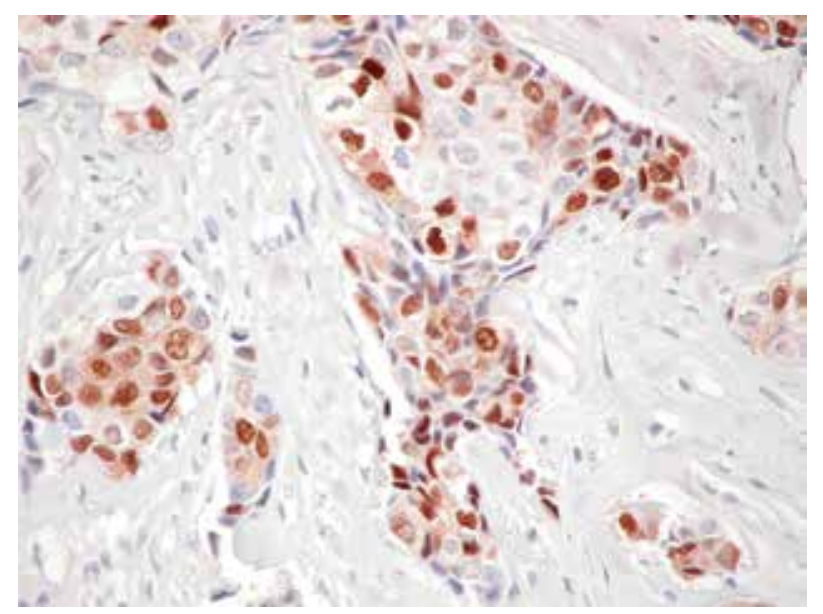

Fig. 1. Showing positive nuclear staining of progesterone receptor in invasive ductal carcinoma (IDC) (original magnification 20x)

tions were found between oestrogen receptors and second- (G2) ( $p=0.023)$ and third- (G3) ( $p=0.0027)$ grade cancers. In the case of progesterone receptor, statistically significant differences were found in G2 $(p<0.001)$ and $\mathrm{G} 3$ carcinomas $(p=0.002)$ (Table 3$)$.
Analysis of the pre-operative staging of cancers studied and expression of steroid receptors showed that the largest group expressing ER were cancers in T2 stage (46\%). PR-positive response was most frequently found in cancers in stages T2 (44\%) and T1c (40\%). In the case of invasive cancers assessed as T1b, positive response to the ER was seen in 9\% of tumours, and PR expression was found in $10 \%$ (Table 3). Statistically significant differences were found for both steroid receptors in the case of tumours in T4 stage (for ER, $p=0.0191$ for PR, $p=0.01228$ ) (Table 3). We also assessed the lymph node status and its relationship to the expression of steroid receptors. In patients without metastasis to regional lymph nodes (pN0), 63\% of invasive carcinomas showed positive reaction for $E R$, and $62 \%$ showed PR-positive reactions. In patients with metastases to deep inguinal lymph nodes (pN3) a positive response to ER was seen in 5\% of cancers, as was in the case for PR (Table 3).

Statistically significant differences were shown between ER and pNO tumours ( $p=0.0443$ ) (Table 3). The results were compared for the expression of oestrogen and progesterone receptors. Analysis of data shows that the highest percentage of patients with invasive breast cancer showed a positive response to both steroid receptors 
$(E R(+) / P R(+))(63.6 \%)$. The smallest group consisted of patients who had a positive reaction to $P R$ and negative reaction to $\operatorname{ER}(\operatorname{PR}(+) / \operatorname{ER}(-))(3.5 \%)$. As many as $22.1 \%$ of women with invasive breast cancer had no reaction to steroid receptors

\section{Discussion}

Oestrogen receptor expression is a recognised marker of breast cancer in women. In normal epithelium of female mammary gland ER is detected in $7-17 \%$ of cells. It is estimated that approximately $70-80 \%$ of breast tumours in women express ER. These tumours are characterised by slower growth, differentiation, and better prognosis with a suitable treatment regimen, which correlates with the length of survival after surgical removal [17].

In our study, in women younger than 50 years, the expression of oestrogen receptors was found in $78 \%$ of cases. In postmenopausal women positive nuclear reaction for ER was observed in $73 \%$ of patients. Women in whom positive reaction for ER occurs in more than 10\% of tumour cells are classified as suitable for hormonal therapy, as in this group of people this kind of treatment is effective [18, 19]. If the reaction is observed in $1-10 \%$ of cells, it means a fragile sensitivity to hormonal treatment. In routine pathological diagnosis not only the percentage of tumour cells showing nuclear colour reaction is taken into consideration, but also the intensity of the reaction [20].

Research by Potemski et al. in 2007 shows that there is a correlation between the level of steroid receptor expression and survival in patients treated with hormonal therapy for breast cancer [21]. Research shows that the best prognosis is seen in patients with the highest expression of oestrogen and progesterone receptors, as well as patients in whom both receptors were present at the same time [21]. In our study, ER and PR expression occurred simultaneously in most patients (63.6\%). Potemski et al. (2007) obtained similar results and also showed that the greater the level of receptor expression [21], the lesser the mortality. Such data may indicate the role of the progesterone receptor as a factor increasing the predictive value of ER.

Elledge et al. (2000) [22] observed the relationship between the percentage of cells showing positive nuclear staining with anti-ER and response to tamoxifen, and survival [22] in women with metastatic breast cancer.

Bardou et al. (2003) [23] found, in women undergoing hormonal adjuvant therapy, that patients with positive response to nuclear oestrogen and progesterone receptors had a lower risk of death compared with patients in whom there was no positive response to both receptors [23]. It was proven that pharmacological chemoprophylaxis with tamoxifen is effective in cases of tumours positive for nuclear oestrogen receptors, and it reduces the risk to 69\% [24-26]. However, there are scientific reports showing that tamoxifen has undesirable effects, such as osteoporosis, enhanced blood clotting, and embolisms, as well as increased risk of endometrial and liver cancer [27]. In our study, statistically significant differences were found for the expression of oestrogen and progesterone receptors and tumour size. This relationship was demonstrated in the case of tumours in stage T4 (for ER, $p=0.0191$ for PR, $p=0.01228$ ). From the results of our work we can conclude that the expression of oestrogen and progesterone receptors may be important in assessing the malignancy of cancers. There were significant associations between both steroid receptors and malignancy in $G 2$ and $G 3$ tumours $(\mathrm{ER} / \mathrm{G} 2 p=0.023, \mathrm{ER} / \mathrm{G} 3 p=0.0027, \mathrm{PR} / \mathrm{G} 2 p<0.001$, $\mathrm{PR} / \mathrm{G} 3 p=0.002$ ) (Table 3 ). The role of oestrogens in the process of carcinogenesis is well known. The effects of oestrogens in this process are linked to their direct impact on the target cell and interaction with other exogenous factors: physical, chemical, and viral.

Oestrogens alter the metabolism of carcinogenic substances and impair the immune system $[28,29]$. They stimulate cell proliferation and they induce receptor protein and DNA synthesis both in glandular and stromal organs, which stimulates the development and growth of tumours [30]. These hormones act on target cells by binding the steroid-receptor complex to DNA, altering the transcription of genes [31]. Expression of oestrogen receptors in breast cancers in women is an important prognostic factor and predictor. In the treatment of breast cancer, drugs are applied that inhibit the synthesis of oestrogens (aromatase inhibitors) [32], drugs that lower blood oestrogen levels (luteinising hormone-releasing hormone - LH-RH), and drugs that act on oestrogen receptors themselves [33]. Approximately $60 \%$ of patients with breast cancer exhibit the presence of both oestrogen and progesterone receptors. In approximately $20 \%$ of patients, the presence of only one of the receptors has been found, in the rest, receptors are not expressed. Expression of receptors is associated with age, and it is often found in older patients [34]. In the case of adjuvant therapy for breast cancer, patients with confirmed presence of oestrogen receptors obtain greater benefit from adjuvant tamoxifen treatment than patients who do not express any of these receptors [35].

Studies Skotnicki et al. (2012) demonstrated that invasive lobular carcinomas were characterised by a lack of E-cadherin expression, high rate of steroid receptor expression, low rate of P53 and c-erb-B2 expressing tumours, low MIB-1 labelling index, and low S-phase fraction, as well as high rate of diploid lesions [36].

Zowczak-Drabarczyk et al. (2013) in their study evaluated the plasma total antioxidant capacity (TAS) in breast cancer patients in relation to ER $\beta$ expression. Based on their studies, the authors concluded that the plasma TAS was significantly decreased in breast cancer patients in comparison to controls, independently of hormonal and lymph node status. The TAS level was not significantly different between breast cancer subgroups either in relation to the ER $\beta$ expression or considering the steroid receptor status, even in the selected lymph node-negative subgroup. The authors observed a tendency towards higher TAS level in all ER $\beta$-negative breast cancer subgroups. A study conducted by Zowczak-Drabarczyk et al. (2013) confirmed enhanced consumption of plasma antioxidants in breast cancer patients. These studies can be considered as an attempt to determine ER $\beta$ isoforms along with pa- 
rameters of redox status, which might enable better understanding of their mutual influence [37].

Research by Čolović et al. (2014) showed that immunosuppressive therapy and androgenic steroids can promote the formation of breast carcinoma in long surviving patients with aplastic anaemia. Their research indicated that a new therapy option is needed for estimation and evaluation, to avoid the consequence of cancer occurrence [38].

Because of the importance of receptor status in cancer cells as a predictive factor, determination of ER status is mandatory in all patients. At this stage, determination of the presence of oestrogen receptors in cancer cells is the only universally recognised and applied prognostic factor. It is known that the main prognostic factors in breast cancer are tumour size, number of involved lymph nodes, the type and grade of malignancy, and the presence of oestrogen and progesterone receptors. Based on our own studies and literature, it appears that the ER(+) state is an indicator of good prognosis, because it indicates less aggressive cancers, in which overall survival and disease-free time is longer in comparison with ER(-) tumours. Determination of ER status may have significant clinical value. Therefore, this marker is widely used in routine pathological diagnosis. However, it is necessary to conduct large prospective clinical trials in which ER status can be determined taking into account two types of oestrogen receptors: $E R \alpha$ and ER $\beta$.

The study should be designed so that, through statistical analysis, it would be possible to answer questions about the role of $E R \alpha$ and $E R \beta$ and their correlation with the PR expression as well as patient age, tumour size, and number of involved lymph nodes. Existing knowledge about the predictive and prognostic significance of ER in cancer is limited and the results are often inconclusive. Very interesting results were obtained in the study of the role of oestrogen receptor $\beta$, which was conducted on cell lines. A study on the MCF-7 cell line expressing only oestrogen receptor $\alpha(E R \alpha(+))$ but not $\beta$ has shown that estradiol potentiated proliferation in these cells. After the introduction of ER $\beta$ to the same cells, estradiol exerted an inhibitory effect on proliferation by preventing the transcription of c-myc, cyclin D1, and cyclin A genes and increasing the expression of p21 and p27. These results indicate that oestrogen receptors $\alpha$ and $\beta$ may have opposite effects on cell proliferation and tumour formation. On the basis of a number of studies, researchers speculate that the presence of $\beta$ receptors in tumour cells may prove to be a beneficial prognostic factor. Determination of steroid receptor presence in breast cancer cells is one of the main factors influencing the choice of adjuvant treatment. The predictive role of steroid hormone receptors in breast cancer is certain, but there are aspects of their prognostic significance that remain the subjects of numerous studies and controversies.

In conclusion:

1. Expression of oestrogen receptor is related to age and menopausal status.

2. Expression of ER is more likely to be observed in breast cancers in older women than in younger women.
3. Expression of ER and PR is not constant and varies with the progression of the disease.

4. The presence of ER is a good prognostic indicator, because it is an indicator of less aggressive tumours, where overall survival and disease-free time is longer in comparison with $\mathrm{ER}(-)$ tumours.

The authors declare no conflict of interest.

Study was carried out at the Department of Pathology, Military Medical Institute in Warsaw, Szaserów 128, 04-141 Warsaw, Poland.

I sincerely thank Dr J. Patera for help in implementing the project.

\section{References}

1. Thorpe SM. Estrogen and progesterone receptor determinations in breast cancer. Technology, biology and clinical significance. Acta Oncol 1988; 27: 1-19.

2. Reiner A, Neumeister B, Spona J, Reiner G, Schemper M, Jakesz R. Immunohistochemical localization of estrogen and progesterone receptor and prognosis in human primary breast cancer. Cancer Res 1990; 50: 7057-61.

3. Pertschuk LP, Kim DS, Nayer K, et al. Immunocytochemical estrogen and progestin receptor assays in breast cancer with monoclonal antibodies. Histopathologic, demographic, and biochemical correlations and relationship to endocrine response and survival. Cancer 1990; 66: 1663-70.

4. Elledge RM, Green S, Pugh R, et al. Estrogen receptor (ER) and progesterone receptor (PgR), by ligand-binding assay compared with $\mathrm{ER}, \mathrm{PgR}$ and $\mathrm{pS} 2$, by immuno-histochemistry in predicting response to tamoxifen in metastatic breast cancer: a Southwest Oncology Group Study. Int J Cancer 2000; 89: 111-7.

5. Hawkins RA. How best to express oestrogen receptor activity. Eur J Cancer 2000; 36 Suppl 4: S21-3..

6. Nadji M, Gomez-Fernandez C, Ganjei-Azar P, Morales AR. Immunohistochemistry of estrogen and progesterone receptors reconsidered: experience with 5,993 breast cancers. Am J Clin Pathol 2005; 123: 21-7.

7. Lower EE, Glass EL, Bradley DA, Blau R, Heffelfinger S. Impact of metastatic estrogen receptor and progesterone receptor status on survival. Breast Cancer Res Treat 2005; 90: 65-70.

8. Stonelake PS, Baker PG, Gillespie WM, et al. Steroid receptor, pS2 and cathepsin D in early clinically node-negative breast cancer. Eur J Cancer 1994; 30A: 5-11.

9. Ogawa Y, Moriya T, Kato Y, et al. Immunohistochemical assessment for estrogen receptor and progesterone receptor status in breast cancer: analysis for a cut-off point as the predictor for endocrine therapy. Breast Cancer 2004; 11: 267-75.

10. Berger U, McClelland RA, Wilson P, et al. Immunocytochemical determination of estrogen receptor, progesterone receptor, and 1,25dihydroxyvitamin D3 receptor in breast cancer and relationship to prognosis. Cancer Res 1991; 51: 239-44.

11. Takashima T, Onoda N, Ishikawa T, Ogawa Y, Kato Y, Fujimoto Y, Sowa M, Hirakawa K. Prognostic value of combined analysis of estrogen receptor status and cellular proliferative activity in breast cancer patients with extensive lymph mode metastases. Oncol Rep 2001; 9: 589-94.

12. Chow IW, Ho P. Hormonal receptor determination of 1,052 Chinese breast cancers. J Surg Oncol 2000; 75: 172-5.

13. Bozcuk H, Uslu G, Peştereli E, Samur M, Ozdoğan M, Karaveli S, Sargin F, Savaş B. Predictors of distant metastasis at presentation in breast cancer: a study also evaluating associations among common biological indicators. Breast Cancer Res Treat 2001; 68: 239-48.

14. Branković-Magić M, Janković R, Nesković-Konstantinović Z, Nikolić-Vukosavljević D. Progesterone receptor status of breast cancer metastases. J Cancer Res Clin Oncol 2011; 128: 55-60. 
15. Allemani C, Sant M, Berrino F, et al. Prognostic value of morphol ogy and hormone receptor status in breast cancer - a population-based study. Br J Cancer 2004; 91: 1263-8.

16. Tsutsui S, Ohno S, Murakami S, Hachitanda Y, Oda S. Prognostic value of epidermal growth factor receptor (EGFR) and its relation ship to the estrogen receptor status in 1029 patients with breast cancer. Breast Cancer Res Treat 2002; 71: 67-75.

17. Barzanti F, Dal Susino M, Volpi A, et al. Comparison between different cell kinetic variables in human breast cancer. Cell Prolif 2000; 33: 75-89.

18. Goldhirsch A, Glick JH, Gelber RD, Coates AS, Thürlimann B, Senn HJ; Panel members. Meeting highlights: international expert consensus on the primary therapy of early breast cancer 2005. Ann Oncol 2005; 16: 1569-1583.

19. Goldhirsch A, Coates AS, Gelber RD, GlickJH, Thürlimann B, Senn HJ; St Gallen Expert Panel Members. First-select the target: better choice of adjuvant treatment for breast cancer patients. Ann Oncol 2006; 17: 1772-6.

20. McCarty KS Jr, Miller LS, Cox EB, Konrath J, McCarty KS Sr. Estrogen receptor analyses. Correlation of biochemical and immunohis tochemical methods using monoclonal antireceptor antibodies. Arch Pathol Lab Med 1985; 109: 716-21.

21. Potemski P, Kusińska R, Kubiak R, et al. The predictive value and prognostic significance of the degree of expression of steroid receptors in breast cancer operation. Oncol Pol 2007; 10: 49-54.

22. Elledge RM, Green S, Pugh R, et al. Estrogen receptor (ER) and progesterone receptor (PgR), by ligand-binding assay compared with $\mathrm{ER}, \mathrm{PgR}$ and $\mathrm{pS2}$, by immuno-histochemistry in predicting response to tamoxifen in metastatic breast cancer: a Southwest Oncology Group Study. Int I Cancer 2000; 89: 111-7.

23. Bardou VJ, Arpino G, Elledge RM, Osborne CK, Clark GM. Proges terone receptor status significance improves outcome prediction over estrogen receptor status alone for adjuvant endocrine therapy in two large breast cancer databases. J Clin Oncol 2003; 21 1973-9.

24. Barrett-Connor E. Raloxifene: risks and benefits. Ann N Y Acid Sci 2001; 949: 295-303.

25. Coombes RC, Hall E, Gibson LJ, et al. A randomized trial of exemestane after two to three years of tamoxifen therapy in postmenopausal women with primary breast cancer. N Engl J Med 2004, 350: 1081-92

26. Schiff R, Massarweh S, Shou J, Osborne CK. Breast cancer endocrine resistance: how growth factor signaling and estrogen receptor coregulators modulate response. Clin Cancer Res 2003; 9 . 447S-54S.

27. Utsumi T, Yoshimura N, Takeuchi S, Ando J, Maruta M, Maeda K, Harada N. Steroid sulfatase expression is an independent predictor of recurrence in human breast cancer. Cancer Res 1999; 59: 337-81.

28. Weatherman RV, Scanlan TS. Unique protein determinants of the subtype-selective ligand response on the estrogen receptors (Ero and ER $\beta$ ) at AP-1sites. J Biol Chem 2001; 276: 3827-32.

29. Tkaczyk M, Kalita K. Estrogen receptor $\beta$-structure, regulation and function. Advanc Biochem 2001; 47: 72-9.

30. Speirs V, Kerin MJ. Prognostic significance of oestrogen receptor beta in breast cancer. Br J Surg 2000; 87: 405-9.

31. Suzuki T, Morlya T, Ishida T, Kimura M, Ohuchi N, Sasano H. In situ production of estrogens in human breast carcinoma. Breast Cancer 2002; 9: 296-302.

32. Tremblay MR, Boivin RP, Lu-The V, Poirier D. Inhibitors of type 117 beta-hydroxysteroid dehydrogenase with reduced estrogenic activity: modifications of the positions 3 and 6 of estradiol. J Enzyme Inhib Med Chem 2005; 20: 153-63.

33. Honma N, Takubo K, Sawabe M, et al. Estrogen-metabolizing enzymes in breast cancers from women over the age of 80 years. J Clin Endocrinol Metab 2006; 91: 607-13.

34. Piekarski J. Estrogen and progesterone receptors in breast cancer state of the art. Contemp Oncol (Pozn) 2005; 9: 371-379.

35. Nadji M, Gomez-Ferenandez C, Ganjei-Azar P, Morales AR. Immu nohistochemistry of estrogen and progesterone receptors reconsidered experience with 5.993 breast cancers. Am J Clin Pathol 2005; 123: 21-27.
36. Skotnicki P, Ryś J, Blecharz P, Reinfuss M, Jakubowicz J, Kruczak A, Lackowska B. Invasive lobular carcinoma of the breast: cytometric and immunhistochemical characteristics of 96 cases. Pol J Pathol 2012; 2: 112-20.

37. Zowczak-Drabarczyk MM, Murawa D, Kaczmarek L, Połom K, Litwiniuk M. Total antioxidant status In plasma of Brest cancer women In relation to ER $\beta$ expression. Contemp Oncol (Pozn) 2013; 17: 499-503.

38. Čolović M, Todorović M, Čolović N, Terzic T, Karadzic K, Jurišić V. Appearance of estrogen positive bilateral breast carcinoma with HER2 gene amplification in a patient with aplastic anemia. Pol J Pathol 2014; 65: 66-9.

\section{Address for correspondence}

\section{Dr Anna M. Badowska-Kozakiewicz}

Department of Biophysics and Human Physiology

Medical University of Warsaw

Żwirki i Wigury 61

02-091 Warsaw, Poland

tel./fax +48226287846

e-mail: abadowska@op.pl

Submitted: 5.01 .2014

Accepted: $\quad 7.08 .2014$ 